\title{
Knowledge management and academic performance moderating role of organizational structure: Abdelmalek essaadi university case
}

\author{
Yassine BOUSSENNA
}

National School of Business and Management Tangier, Abdelmalek Essaadi University, Morocco

\begin{abstract}
In a knowledge-based economy, and a context of fierce international competition that spares no field. universities as organizations highly dependent on knowledge should pay special attention to it and its management, in such a way that the effective management of this asset is a key factor in building a competitive advantage and became the cornerstone of efforts to improve the performance of the university.

In addition, it has long been demonstrated that better knowledge management has a positive impact on organizational performance. However, it is not yet clear how this process is to be achieved in academia and particularly in developing countries such as Morocco.

On the other hand, and throughout the literature, several factors affect positively KM initiatives in public organizations and more specifically in universities are discussed. Some of these are the same as those found for private organizations and others are specific to public organizations. Most authors cite the organizational structure.

This work has the main objective to verify the moderating role of organizational structure on the intensity of the relationship between the application of knowledge management and organizational performance of Abdelmalek Essaadi University. by collecting the views of the Abdelmalek Essaadi University teacher-researchers, through a hypotheticodeductive reasoning approach and a quantitative working method. Our questionnaire was administered to a representative sample of 88 teacher-researchers from the different institutions of the university under study.

The results obtained prove the moderating and positive role of organizational structure, on the intensity of the relationship between the application of the K.M and (Training, research, publication, and governance) as indicators of organizational performance with a degree of impact of $1.1 \%$.
\end{abstract}

Keywords: organizational structure, knowledge management, academic performance.

\section{INTRODUCTION}

The transition from a post-industrial economy to a knowledge-based economy has given rise to a new phase in economic history that began in the 1990s.

The knowledge currently occupies an important and even growing place in the process of building societies, some qualifying it as the main engine of economic and social growth of society. The accumulation and use of knowledge have become major factors in the process of economic development and are increasingly the basis of a country's competitive advantage in the global economy. Despite the advent of these new challenges facing the university, most developing and transition countries continue to struggle with the difficulties arising from inadequate solutions to the nagging problems facing their educational systems.

Today universities are subject to similar pressures like different organizations to gain a place in the markets. the government and stakeholders are more concerned with the performance of universities, therefore these important changes in the competition have prompted professors and universities to adopt a 
Modern management system similar to companies, where students are currently treated as clients ( Hilman \& Abubakar, 2017).

In the Moroccan context, the higher education sector is constantly floundering with many problems, despite the progress noted and the multitude of reforms that followed one another, especially from the beginning of the third millennium. Always the quest for the performance of the university is at the heart of the Royal Speeches and government controversies (Bouayad et al 2017., p 386).

The Moroccan university is called upon to accompany, through training and scientific research, the reforms and the major structuring projects initiated by the Kingdom.

Universities, known as organizations responsible for the production, storage, and sharing of knowledge, have seen the need to participate in the construction of a knowledge economy (El kharraz \& Boussenna 2020 ).

In addition, several studies have addressed the issue of the importance of the application of K.M for organizations such as improving innovation and creativity, product quality, and organizational performance ( le et al, 2009; Mills \& Smith, 2011; Reich et al, 2013; Lee \& Tseng, 2014; Alaarj et al,.2016; Novak, 2017; Adams, \& Graham, 2017; Shamia et al.,2018; Abubakar, et al,2018; Ernest et, al 2020; Sahibzada et al, 2020; Salama, 2020; Wenjiao \& Yang 2020; El kharraz \& Boussenna, 2020 ).

On the other hand, and throughout the literature, several factors positively affecting KM initiatives in public organizations and specifically in universities are discussed. For Ranjan and Bhatnagar (2008), these are factors or parameters necessary for the continued success of an organization and these factors represent the areas of management that require special and continuous attention to achieve high performance. Some are the same as those identified for private organizations and others are specific to public organizations. Most authors (Butler \& Murphy, 2007; Cong, 2008; Ansari et al. 2012) cite several factors; but in this article, we will focus on the organizational structure.

An organizational structure must be flexible to promote the distribution of knowledge within the organization. In contrast, a centralized and overly formalized structure will prevent communication between units and the profusion of the distribution of ideas. The communication channels will not favor a fluid diffusion and efficient sharing of knowledge. structure was particularly highlighted as a factor affecting the successful implementation of KM. Thus, horizontal organizations are more convenient for the information and knowledge era due to the flexibility that this type of organization offers (Ansari et al. 2012).

It remains to point out at this level that the organizational structure is a success factor of knowledge management and also a tool of performance, but how it can play a moderating role between the two is not well demonstrated and especially in the university context. which leads us to the study of this problem and more specifically the moderating effect of the organizational structure on the relationship between the application of knowledge management and organizational performance at Abdelmalek Essaadi University and from the point of view of teacher-researchers.

Thus, our reflection will focus on the treatment and analysis of the following three elements:(1) Literature review and development of hypotheses (2) Research methodology and Results (3) discussion of the results of the study.

\section{LITERATURE REVIEW AND HYPOTHESIS DEVELOPMENT}

The enormous amount of information in our daily life and the continuous work to organize it in order to exploit it in the best possible way, has led to the emergence of a new concept known as knowledge management. 
In addition, the term "performance" has been much talked about. It is a widely used vocabulary in the field of management. The quest for performance was the ultimate goal of all organizations.

\subsection{KNOWLEDGE MANAGEMENT IN THE UNIVERSITY CONTEXT}

With the rapidly changing economic environment, the role of universities or higher education institutions as knowledge providers have been examined and challenged by different stakeholders. Indeed, Academic institutions, especially higher education institutions such as universities, are considered as "knowledge centers", where various activities are carried out for the generation, preservation, dissemination, and application of knowledge. Teachers, students, and researchers are an integral part of academic institutions and all of them are engaged in the above activities.

Universities create knowledge through research, share knowledge through teaching and learning, and transfer knowledge to society through consultation and a well-trained workforce (Ramachandran et al., 2013). On the other hand, several types of research have shown that the majority of universities do not have an explicit KM strategy even though they are aware of the importance of such a strategy, as its implementation remains difficult.

\subsubsection{The KNOWLEDGe Management Process in UNIVERSITIES}

Knowledge assets are managed in several ways, namely: through capitalization, sharing, and knowledge creation (Ermine, 2008).

There is no unified agreement among authors and researchers regarding the number of K.M processes, as different researchers define them in different ways (Costa \& Monterio, 2016) and with several models as they are defined as three stages: knowledge generation, knowledge codification, and knowledge transfer. Or four consisting of Acquiring, storing, sharing, and applying knowledge or it is a five-step process consisting of (knowledge acquisition, knowledge formation, knowledge transfer, knowledge storage, and application) (Abidi et al 2018, p 5 ).

Becerra et al, (2004) integrated the empirical research findings of Nonaka (1994) (socialization, externalization, internalization, combination), and distinguished four knowledge management processes: knowledge discovery, knowledge capture, knowledge sharing, and knowledge application.

On our part in this work, we will opt for the most used model and the most adapted to the universities in four stages consisting of acquiring, storing, sharing, and using knowledge, (Alavi \& leidner, 2001, Laudon \& Laudon, 2002, Doueihi, 2009).

\subsection{Organizational Performance at the University}

Level Performance measurement is fundamental to all organizations including universities. Today universities are under similar pressures as different organizations to have a place in society. Significant changes in the competition have prompted universities to adopt a new management system similar to businesses in that students are currently treated as customers. In addition, there are increasing demands from stakeholders (Hilman \& Abubakar, 2017).

Universities must ensure and provide students with high-quality service. They must produce graduates who can adapt to the challenges of the developing society. Other research has focused on teaching and research as indicators of performance measurement in universities (Manjarrés et al.,2009; Lukman et al.,2010; Asif et al., 2013; Asif \& Searcy, 2014).

Other researchers believe that the production of services for the community is an indicator of performance (Badri \& Abdulla, 2004; Patel et al, 2011). On the other hand, the student graduation rate remains a primary 
indicator of university performance. Hilman \& Abubakar, (2017) stated that the undergraduate loss rate should be taken into account when assessing university performance.

\subsubsection{THE NEED FOR PERFORMANCE ASSESSMENT FOR UNIVERSITIES}

Performance evaluation is now at the heart of reforms in higher education and research in Morocco. It is part of the general revision of public policies which integrates project logics (objectives, means, results), where for a long time means logics prevailed. This question of measuring the performance of universities seems to have been partly resolved today by the evaluation systems set up by university supervisory bodies and international rankings. Indeed, these seem to define the fundamentals of the university by which it can be managed.

\subsection{ORGANIZATIONAL STRUCTURE}

The term "organizational structure" comes from organizational theory and refers to the hierarchical framework that defines the internal division of labor within an organization. An organizational structure is used to structure an organization according to its objectives ( to increase production, to secure the future, to promote growth). It helps to clarify the following points:

- What functions and departments exist in the organization?

- What responsibilities do they have?

- $\quad$ How is the network of relationships structured?

- What does the hierarchy of information and orders look like?

\subsubsection{THE ORGANIZATIONAL STRUCTURE DEFINITION}

Organizational structure refers to how an organization allocates human resources and tasks to achieve its objectives.

For (Bauer \& Erdogan, 2012) The organizational structure clarifies and determines the distribution of tasks within the organization and clarifies the formal coordination tools and interaction patterns to follow and control responsibilities, to achieve organizational goals.

Organizational structure can also be defined as a schematic representation of the hierarchical and functional links of a company or an organization, which makes it possible to specify the levels of responsibility and the channels of communication.

- $\quad$ For Peter Drucker "There is more than one 'best way' to organize work. It all depends on the type of task or the type of environment you are dealing with."

"Simple structure and adhocracy often prove most effective when the environment is unstable. "

- Gareth Morgan, on the other hand, says, "Problems of structure, no matter how big, are only a small part of the issue of organizational effectiveness. "

"The simplicity of the basic structure facilitates flexibility in organization. The best companies make better use of task forces, project centers, and other ad hoc arrangements that get things done. They also seem to be constantly reorganizing. They are, but most of that reorganization is marginal. The basic shape rarely changes that much."

As for Tom Peters "Build and maintain a simple, flexible, flat organization. There is nothing inherently wrong with bureaucracy. Procedures are necessary for any well-functioning organization. But too much red 
tape hinders progress, saps employee enthusiasm, and burns out their energy. With this in mind, cut out every possible vestige of unnecessary bureaucracy such as unnecessary layers of management, an abundance of rules and regulations, outdated formalities, etc. Make the structure and processes as simple as possible, not only for employees but also for suppliers and customers. What's important is that the work is easy to do. "

For Alfred, Chandler's Structure influences adaptability and innovation. Also, in the preface to the new edition of Strategy and Structure, Chandler qualifies the link that emerges from his study, stating that "structure has had as much impact on strategy as a strategy has on the structure.

\subsection{HYPOTHESIS DEVELOPMENT}

\subsubsection{LINK BETWEEN STRUCTURE AND ORGANIZATIONAL PERFORMANCE}

Organizations need a clear structure to function smoothly and grow at the same time. Without structure, there is no clear purpose for either management or employees. No one knows exactly what they are responsible for and to whom they are accountable. This creates confusion and stress and makes conflicts of responsibility almost inevitable. The result is a lack of coordination and slowness in decision-making processes, which can have a long-term impact on the economic efficiency and performance of an organization.

A well-thought-out organizational structure, which defines management chains, controls margins and communication channels in an understandable way, allows all energies to be aligned with the organization's objectives. This is achieved, for example, by clarifying the value chain, creating an overview of work areas, and even reducing organizational costs. It also helps new employees to orient themselves within the organization, recognize their superiors and subordinates, and to understand the bigger picture, as well as their career prospects within the organization. A clear organizational structure thus contributes to the job satisfaction and sense of security of employees.

Several authors have discussed the impact of structure on organizational performance Hall (1979) suggests that structure has two main functions: first, the behavior of individuals, and second, organizational performance. emphasizes the importance of structure on performance and efficiency.

\subsubsection{LINK BETWEEN ORGANIZATIONAL STRUCTURE AND KNOWLEDGE MANAGEMENT}

Organizational structure refers to the way in which an organization allocates human resources and tasks in order to achieve its goals (Helms 2006, p 629). The organizational structure thus determines the decisionmaking process as well as the responsibilities for materials, resources, and human processes.

An organizational structure must be flexible to promote the distribution of ideas and knowledge within the organization. In contrast, a centralized and overly formalized structure will prevent communication between units and the profusion of the distribution of ideas. The communication channels will not favor a fluid diffusion and efficient sharing of knowledge in such a structure. Organizational structure was particularly highlighted as a factor affecting the successful implementation of KM. Thus, horizontal organizations are more convenient for the information and knowledge era due to the flexibility that this type of organization offers (Ansari et al. 2012, p.215).

The main factors related to organizational structure identified in the literature are (Ansari et al. 2012, p.215; Cong 2008, p.111; Butler \& Murphy 2007, p 615).

-The degree of centralization.

- The degree of formalization;

- Communication flows. 
At the same time, several researchers and practitioners have noticed the positive relationship between organizational structure and application of knowledge management, also between structure and performance ( Meijaard et al 2005, JungYang, 2010, Hosseinpour \& Tabari, 2016 ) .

The various theoretical arguments and empirical studies presented previously allowing us to deduce the second sub-hypothesis of the central hypothesis 2 :

The organizational structure positively moderates the relationship between the application of knowledge management and organizational performance of the university Abdelmalek Essaadi from the point of view of research teachers.

\section{RESEARCH METHOD}

\subsection{EPISTEMOLOGICAL FRAMEWORK AND METHODOLOGICAL CHOICES}

Our research is influenced by the inscription of our work in an adequate epistemological paradigm according to the conceptual framework, the hypotheses, and the relationship between the variables.

To be precise, we will respond to all the points mentioned above which summarize our epistemological framework and our methodological choice through the table below:

TABLE I. epistemological framework and methodological choices

\begin{tabular}{|c|c|}
\hline Methodological axis & Our choice \\
\hline The Epistemological Paradigm & The post positivism \\
\hline The current of thought & Scientific realism \\
\hline the reasoning process & The hypothetical-deductive approach \\
\hline The working method & It will be quantitative \\
\hline empirical method of work & The Survey \\
\hline Data collection tool & The questionnaire \\
\hline The nature of the data & $\begin{array}{l}\text { The data are interpretations of reality that can be } \\
\text { considered as objective. }\end{array}$ \\
\hline The nature of reality in relation to the actors & We admit that reality exists independently of us. \\
\hline $\begin{array}{l}\text { The relationship between the researcher and } \\
\text { the object of the study }\end{array}$ & $\begin{array}{l}\text { We admit that it has an independence between } \\
\text { us and our subject of study. }\end{array}$ \\
\hline the testing process & $\begin{array}{l}\text { The research is part of a model testing approach } \\
\text { developed from theory. }\end{array}$ \\
\hline
\end{tabular}

Source: author

\subsection{THE SAMPLE OF OUR STUDY}


We administered a questionnaire to a representative sample of 88 teacher-researchers from the various institutions of Abdelmalek Essadi University.

TABLE 2. Sample size calculation

\begin{tabular}{|c|c|c|c|c|}
\hline $\begin{array}{c}\text { Populatio } \\
\text { n size }\end{array}$ & $\begin{array}{c}\text { confidenc } \\
\text { ellevel }\end{array}$ & $\begin{array}{c}\text { Margin } \\
\text { of error }\end{array}$ & Formula & Our sample size \\
\hline $\begin{array}{c}1000 \\
\text { teacher- } \\
\text { research } \\
\text { ers }\end{array}$ & $95 \%$ & $10 \%$ & $\frac{\frac{i}{t} \times(l-p)}{\partial}$ & $\begin{array}{c}\text { n=88 teacher- } \\
\text { from different } \\
\text { institutions of } \\
\text { the university }\end{array}$ \\
\hline
\end{tabular}

Source: author

\subsection{OUR Data Collection TOOL}

In order to meet the needs of our study, a questionnaire with nine indices and 40 questions was designed. However, we feel it is necessary to ensure the validity and reliability of our tool.

\subsubsection{CONTENT VALIDITY :}

To ensure the content validity of our questionnaire, we followed the steps below: First, we conducted extensive research on the topic and then specified the structure of the field under study. Then we consulted specialists in the field of knowledge management and management control, primarily teachers and practitioners, and finally, we made the necessary corrections, we eliminated almost 20 questions and reworded many questions to finally have a questionnaire that was valid in terms of content.

\subsubsection{ANALYSIS OF QUESTIONNAIRE RELIABILITY}

To address the issue of the reliability of the questions asked in a test, we calculated Cronbach's alpha coefficient. The table below shows the value of the coefficient for all chapters using SPSS software:

TABLE III. The reliability of the questionnaire

\begin{tabular}{|c|c|c|}
\hline Study Variables & Chapter & $\begin{array}{c}\text { Cronbach's alpha } \\
\text { coefficient }\end{array}$ \\
\hline Creation & $1-4$ & 0.822 \\
\hline Storage & $5-7$ & 0.838 \\
\hline Sharing & $8-11$ & 0.784 \\
\hline Use & $12-15$ & 0.971 \\
\hline Knowledge management & $1-15$ & $\mathbf{0 . 9 5 7}$ \\
\hline Training & $16-20$ & 0.928 \\
\hline Research & $20-25$ & 0.936 \\
\hline Publication & $25-30$ & 0.972 \\
\hline Governance & $30-35$ & 0.977 \\
\hline Organizational performance & $16-35$ & $\mathbf{0 . 9 7 3}$ \\
\hline Organizational Structure & $36-40$ & 0.736 \\
\hline
\end{tabular}

Source: author

From the data in the table above we notice that the value of Cronbach's alpha for all chapters in our research is between 0.784 and 0.977 .

Therefore, these values are well above 0.7 which confirms the internal consistency and reliability of our questionnaire. 
BOUSSENNA: Knowledge management and academic performance moderating role of organizational...

\section{RESULTS AND DISCUSSIONS}

\subsection{DESCRIPTIVE STATISTICS}

TABle V. Descriptive results of The Organizational Structure

\begin{tabular}{|c|c|c|c|c|}
\hline Organizational Structure & $\begin{array}{c}\text { The } \\
\text { mean }\end{array}$ & S.D & Level & $\begin{array}{c}\text { Classificatio } \\
\text { n }\end{array}$ \\
\hline $\begin{array}{c}\text { At university, the relationship between the } \\
\text { president and subordinates is based on } \\
\text { cooperation. }\end{array}$ & 2,45 & 0,65 & Medium & $\mathbf{1}$ \\
\hline $\begin{array}{c}\text { At the establishment there is a decentralization } \\
\text { of work, which offers the possibility of sharing } \\
\text { knowledge between teachers-researchers. }\end{array}$ & 2,09 & 0,90 & Low & 2 \\
\hline $\begin{array}{c}\text { The organizational structure of the institution is } \\
\text { flexible, which allows for the assimilation of } \\
\text { internal and external environmental variables. }\end{array}$ & 2,00 & 0,60 & Low & 3 \\
\hline $\begin{array}{c}\text { The organizational structure of the } \\
\text { establishment allows the circulation of } \\
\text { knowledge between departments in a vertical } \\
\text { and transversal way. }\end{array}$ & 1,90 & 0,90 & Low & 4 \\
\hline $\begin{array}{c}\text { The organizational structure of the } \\
\text { establishment facilitates the process of } \\
\text { personnel turnover, which contributes to the } \\
\text { transfer of knowledge. }\end{array}$ & 1,72 & 0,75 & Low & $\mathbf{5}$ \\
\hline Overall average & 2,03 & 0.54 & Low & \\
\hline
\end{tabular}

The $T$ value in the table $=1.96$, with a significance level $\alpha=0.05$, and a mean level between (2.34 and 3.67)

According to the above results, we notice that the existing organizational structure at the level of the different institutions of Abdelmalek Essaadi University does not favor the initiatives of applying knowledge management.

From the results below we also note that the item, $<<$ at university The relationship between the president and subordinates is based on cooperation. $>>$ obtained the highest mean of 2.45 and a standard deviation of 0.65 followed by the item $\ll$ At the institution there is a decentralization of work, which offers the possibility of sharing knowledge among teacher-researchers $\gg>$ with a mean of 2.09 and a standard deviation of 0.90 on the third position we find the item $\ll$ The organizational structure of the institution is flexible which allows assimilating the environmental variables in Internal and external > with a mean of 2.00 and a standard deviation of 0.60 . fourthly we find the item $<<$ The organizational structure of the institution allows the circulation of knowledge between departments in a vertical and transversal way ..>> with a mean of 1.90 and a standard deviation of 0.90 lastly we find the item $<<$ The organizational structure of the institution facilitates the process of personnel turnover which contributes to the transfer of knowledge.>> with a mean of 1.72 and a standard deviation of 0.75 .

These results obtained clearly illustrate the lack of presence of the factors of success of knowledge management at the level of the different institutions of Abdelmalek Essaadi University from the point of view of teachers, especially the organizational structure.

\subsection{HYPOTHESIS TESTING :}


TABLE VI. Hierarchical regression moderation analysis showing organizational structure on the relationship between K.M and organizational performance.

\begin{tabular}{|c|c|c|c|c|c|c|c|c|c|c|}
\hline $\begin{array}{c}\text { The dependent } \\
\text { variable }\end{array}$ & \multirow{2}{*}{$\begin{array}{c}\text { The } \\
\text { independent } \\
\text { variable }\end{array}$} & \multicolumn{3}{|c|}{ First model } & \multicolumn{3}{|c|}{ Second model } & \multicolumn{3}{|c|}{ Third model } \\
\hline \multirow{9}{*}{$\begin{array}{c}\text { Organizational } \\
\text { performance }\end{array}$} & & Beta & $\mathbf{T}$ & Sig & Beta & $\mathbf{T}$ & Sig & Beta & $\mathbf{T}$ & Sig \\
\hline & $\begin{array}{c}\text { Knowledge } \\
\text { management }\end{array}$ & 0,878 & 17.012 & 0.000 & & & & & & \\
\hline & $\begin{array}{l}\text { organizational } \\
\text { Structure }\end{array}$ & & & & 0.155 & 6.199 & 0.00 & & & \\
\hline & $\begin{array}{c}\text { Knowledge } \\
\text { management } \\
* \text { Structure }\end{array}$ & & & & & & & 0.104 & 2.040 & 0.044 \\
\hline & $\mathbf{R}$ & & 0.917 & & & 0.155 & & & 0,928 & \\
\hline & $\mathbf{R}^{2}$ & & 0.771 & & & 0.024 & & & 0.922 & \\
\hline & $\Delta R^{2}$ & & 0.771 & & & 0.024 & & & 0.011 & \\
\hline & $\Delta F$ & & 289.40 & & & 2.118 & & & 1.163 & \\
\hline & $\Delta \mathbf{S i g}$ & & 0.000 & & & 0.149 & & & 0.044 & \\
\hline
\end{tabular}

The $T$ value in the table $=1.96$, with a significance level $\alpha=0.05$, and a mean level between $(2.34$ and 3.67)

Table: VI showing the results of hierarchical multiple regression for the first model the value of the correlation coefficient $\mathrm{R}=0.917$, which implies a statistically significant relationship between knowledge management and organizational performance at the level of the different institutions of the University Abdelmalek Essaadi. Note also that the value of $F=289$ showing a positive and significant effect of knowledge management on organizational performance at a significance level $\alpha=0.05$, in the same sense the value of the coefficient of determination $\mathrm{R}^{2}=0.771$ explains that $77.1 \%$ of the variation in organizational performance at the different institutions of the University according to teachers is due to the application of knowledge management. Also, the value of Beta $=0.878$ predicts the variation of organizational performance of 0.878 when there will be an increase in the application of knowledge management by one degree at the level of Abdelmalek Essaadi University from the point of view of research teachers.

Regarding the results of the second model that relates the organizational performance with the organizational structure of each institution we note:

First that the value of the correlation coefficient $\mathrm{R}=0.155$ which implies a statistically significant relationship between the organizational structure and organizational performance at the level of the different institution of Abdelmalek Essaadi University. also note that the value of $F=2.118$ showing a positive and significant effect of knowledge management on organizational performance at a level of significance $\alpha$ less than 0.150 , in the same direction the value of the coefficient of determination $\mathrm{R}^{2}=0.024$ explains that $2.4 \%$ of the variation in organizational performance at the level of the University according to teachers' researchers is due to the change in organizational structure. also, the value of Beta $=0.155$ predicts the variation in organizational performance of 0.155 when there will be an increase in the organizational structure of a degree at the level of Abdelmalek Essaadi University from the point of view of teachers researchers.

About the third model, we added the organizational structure as the third variable by examining its moderating role on the relationship between knowledge management and organizational performance we noticed a slight increase of $1.1 \%$, so that the correlation coefficient with $\mathrm{R}=0.928$ and this increase and statistically significant with a $\mathrm{T}=2.04$ greater than 1.96 of a significance levels $\leqslant 0.05$ showing a value of 0.044 on the table.

\subsection{DISCUSSIONS :}




\subsubsection{DISCUSSIONS DESCRIPTIVE}

Regarding the success factors of knowledge management, it could be shown that there is a lack of presence of the success factors of knowledge management at the level of different institutions of Abdelmalek Essaadi University for the factor structure. which can directly imply the application of the K.M these findings remain consistent with the study of (Al-Mudallal, 2012) which concludes on a lack of presence of the factors of knowledge management at the level of the first Ministry in Jordan from the point of view of officials of the ministry.

On the other hand, our results disagree with the results obtained by (Al Talabani et al, 2015) which recorded a high level of presence of factors (culture, structure, leadership, and ICT) facilitating the application of knowledge management at the level of all universities in the Gaza Strip in Palestine from the point of view of 241 participants between administrators and teachers.

The results obtained indicate that the current organizational structure at the level of the various institutions of Abdelmalek Essaadi University from the point of view of teachers is not conducive to a better application of knowledge management at the university level. Note that these results coincide with the findings of the study conducted by ( Ghorbani et al,2011) which proves the relationship between knowledge management and organizational structure at the level of the Iranian ministry of education from the point of view of 90 officials. Therefore, the managers of Abdelmalek Essaadi University institutions are led to improve the current organizational structure to be adequate for the application of knowledge management through:

- Decentralization of work, which offers the possibility of sharing knowledge among teachers-researchers.

- the circulation of knowledge between departments in a vertical and transversal manner.

- staff turnover, which contributes to knowledge transfer.

\subsubsection{TESTING HYPOTHÉSIS}

The results obtained using hierarchical multiple regression affirm the validity of the central hypothesis. on the presence of a positive and statistically moderating role of the organizational structure on the relationship between the application of knowledge management and organizational performance of Abdelmalek Essaadi University from the point of view of the research teachers

As a result, a slight increase of $1.1 \%$ in the strength of the relationship between knowledge management and organizational performance of the University, with a shift in the primary correlation coefficient from $\mathrm{R}=$ 0.917 to $\mathrm{R}=0.928$ with the addition of the organizational structure as the third variable of the model, so this increase and statistically significant with a $\mathrm{T}=2.04$ greater than 1.96 of a significance levels $\leqslant 0.05$.

This confirms the positive moderating role of the organizational structure on the relationship between knowledge management and organizational performance at the different institutions of Abdelmalek Essaadi University from the point of view of teacher-researchers, with a degree of impact of $1.1 \%$ confirming our hypothesis.

These results coincide with the results obtained by other researchers including the work of Shamia et al, 2018. on the application of the Asian model of knowledge "APO" and its impact on improving the performance of universities in Palestine. The study proves the positive impact of the structure on improving the relationship between knowledge management and performance of universities Palestine and especially $\mathrm{Al}$ Azhar University subject of the study. 
Also, the acquired results are in the same direction of the study of (Novak, 2017), which had as main objective to analyze the different works related to KM processes (creation, storage, transfer, and use)and organizational performance, as well as the relationships between the elements of the knowledge infrastructure (technology, organizational culture, and organizational structure). The majority of the studies reviewed revealed the positive impact of knowledge management practices and/or knowledge infrastructure elements on organizational performance.

his confirms the positive moderating role of the organizational structure on the relationship between knowledge management and organizational performance at the different institutions of Abdelmalek Essaadi University from the point of view of teacher-researchers, with a degree of impact of $1.1 \%$ confirming the second sub hypothesis.

\subsection{TEST OF THE THEORETICAL MODEL}

Using hierarchical multiple regression, we were able to show the impact of the process of knowledge management on the organizational performance of Abdelmalek Essaadi University from the point of view of research teachers.

The results show that the knowledge management process has a positive impact on the organizational performance of the university and that the organizational culture has a positive and moderating role in this relationship.

The figure below presents the results confirming the positive relationship between our variables (Pearson's correlation coefficient is greater than 0.5 for all relationships between variables). This validates the hypothesis of this research and proves the validity of our hypothetical research model:

FIG 1. test the theoretical model.

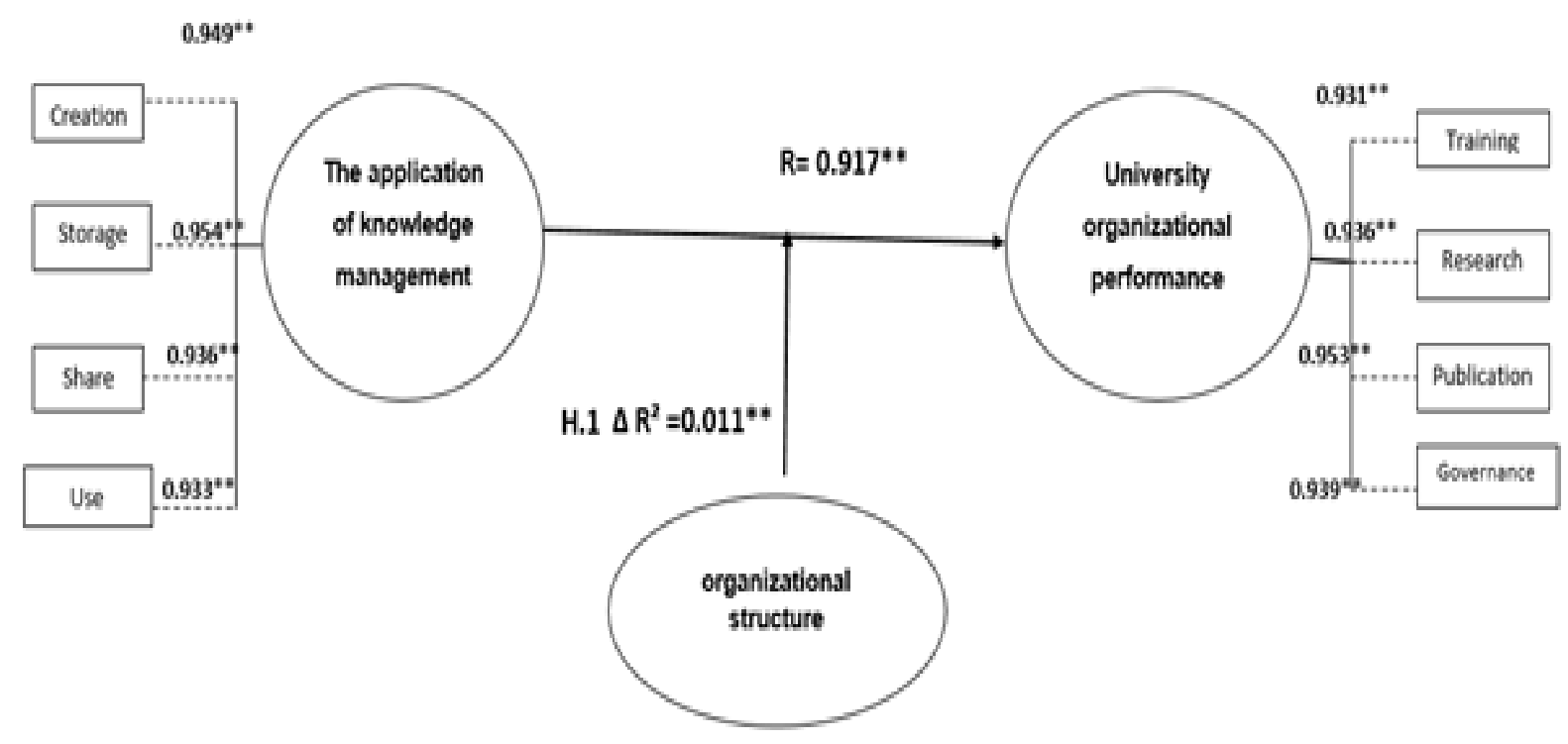


BOUSSENNA: Knowledge management and academic performance moderating role of organizational...

\section{CONCLUSION}

Knowledge management in Moroccan universities is a relatively young field of study. This article has the particularity of mobilizing a rich theoretical corpus, consisting primarily of two reference theories: the theory of resources (Resources Based View) and the theory of knowledge (Knowledge-Based View). The mobilization of these theoretical bases, allowed us to situate our research at the intersection of the knowledge approach, considering the application of knowledge management as a strategic resource, contributing to organizational performance and the development of sustainable competitive advantage for all organizations and including universities, and the approach of key success factors, linking the success of the application of knowledge management to organizational, technical and human factors encompassed in (the structure). Better still, our approach to the problem was strongly anchored in this theoretical corpus, by trying to orient our reflection both theoretically and empirically, by situating it in this conceptual framework.

Indeed, we found that there is a lack of practice of the K.M at the level of Abdelmalek Essaadi University. This article also attempts to explore the phenomenon at the national level, unlike the majority of previous research, oriented mainly to developed countries.

This work has also made a managerial contribution, mainly to Moroccan universities, through the delineation of the different dimensions of the phenomenon. It is first to propose to university managers a clear vision on the importance of the application of K.M in improving the organizational performance of universities, and then, to provide a detailed reading of the various organizational, technical, and human factors impacting the intensity of this relationship through the test of the moderation effect of the organizational structure.

From a methodological point of view, it is quite rare in the research on public organizations to see studies in which the authors have used the method of testing moderating effects, In parallel, The empirical phase of our work offers originality in the study of public organizations and more precisely universities with a quantitative approach, an approach that is increasingly developed in management science.

At the same time, this work has not delved into the issue of organizational performance in the university, which is the ultimate goal of the application of K.M. We believe that this aspect remains unexplored in the literature and deserves to be developed separately, given the complex variables that it may involve.

Also in our future work, we will study other success factors of knowledge management initiatives such as organizational culture, leadership, and information technology.

In addition, an increase in the size of our samples per establishment could perhaps better explain the influence of knowledge management for each establishment. In addition, the choice of a single region (Tangier-Tetouan-Al Hoceima) in this work, pushes us to expand our field of work for future work to cover the national territory in its entirety.

Moreover, it should be noted that this research has important implications for the leaders of Moroccan universities. The confirmation of the hypotheses of our work reminds us that each university must clearly define its strategy based on better knowledge management as a cornerstone of any action aiming at excellence and organizational performance, and consequently the improvement of its competitiveness at the international level. Moreover, our research constitutes a line of thought for researchers wishing to strengthen research related to knowledge management and organizational performance in the university environment and especially in Morocco. 


\section{REFERENCES}

[1] Abidi, W,. Sanchez, M,.Aoiz,G,.(2018), Phenotypic and biochemical diversity in peach [Prunus persica (L.) Batsch] cultivars. Journal of New Sciences. Agriculture and Biotechnology 51 (5): 3171-3178.

[2] Abubakar, A ,. Hilman ,H ,. Kaliappen , N. ( 2018 ). New Tools for Measuring Global Academic Performance, DOI: 10.1177/2158244018790787 journals.sagepub.com/home/sgo.

[3] Adams, F,. \& Graham, K .( 2017 ). Integration, knowledge creation and B2B governance: The role of resource hierarchies in financial performance, Industrial Marketing Management.

[4] Alaarj , S,. Zainal, A, ,. Ummi,S . (2016). Turkey Mediating Role of Trust on the Effects of Knowledge Management Capabilities on Organizational Performance, 12th International Strategic Management Conference, ISM, Antalya .

[5] Alavi , M ., \& Leidner, D. (2001). Review: Knowledge Management and Knowledge Management Systems: Conceptual Foundations and Research Issues. MIS Quarterly, 25(1), 107-136. DOI: 10.2307/3250961.

[6] Al Talbani,N,. Bdair, R,. Al-Ruqub, M..(2015). Requirements for Implementing Knowledge Management in the Palestinian Universities in Gaza Strip. Maryland Series in Contemporary Asian Studies, Vol. 2014 Issue 3, p443-480. 38p.

[7] Al-Mudallal, A. (2012). Impact of Knowledge Management Application on Performance Levels at Palestinian Governmental Institutions: Applied Study Carried at Prime Ministry, unpublished master's dissertation, Islamic University, Gaza.

[8] Ansari, M., Youshanlouei, H,. Mood, M. (2012).A Conceptual Model for Success in Implementing Knowledge Management: A Case Study in Tehran Municipality. Journal of Service Science and Management, 05(02), pp.212-222.

[9] Badri, M,. \& Abdulla,M. (2004). "Awards of excellence in institutions of higher education: an AHP approach", International Journal of Educational Management, Vol. 18 No. 4, pp. 224-42.

[10] Bouayad, A., Rouggani K., Lamchouat, M. (2017). La performance universitaire publique au cœur de la théorie des STAKEHOLDERS, Economie et Kapital, Numéro 12 / pp. 48-78, ISSN:2489-1282.

[11] Bauer, T. N., \& Erdogan, B. (2012). Organizational socialization outcomes: Now and into the future. In C. R. Wanberg (Ed.), Oxford library of psychology. The Oxford handbook of organizational socialization (p. 97-112). Oxford University Press.

[12] Butler,T., Murphy, C. (2007). Implementing Knowledge Management Systems in Public Sector Organisations: A Case Study of Critical Success Factors. In H. Österle, J. Schelp, \& R. Winter, eds. 15th European Conference on Information Systems. University of St. Gallen, pp. 612-623.

[13] Chia-LingLeeHuan-JungYang, (2010) , Organization structure, competition and performance measurement systems and their joint effects on performance https://doi.org/10.1016/j.mar.2010.10.003

[14] Choi, B., \& Lee, H. (2014). Knowledge Management Enablers, Processes, and Organizational Performance: An Integrative View and Empirical Examination, Journal of Management Information Systems / Summer 2003, Vol. 20, No. 1, pp. 179222.

[15] Cong, X., (2008). Towards a framework of knowledge management in the chinese public sector: a case study of china customs. Northumbria University.

[16] Costa, V., Monteiro. (2016). Key knowledge management processes for innovation: a systematic literature review, VINE Journal of Information and Knowledge Management Systems, ISSN: 2059-5891.

[17] Doueihi, M. (2009). La grande conversion numérique Seuil, Paris, 271 , https://doi.org/10.4074/S0336150009002129.

[18] Drucker, P. (1993 )."The rise of the knowledge society." The Wilson Quarterly, vol. 17, no. 2, p. 52+.

[19] El Kharraz, O., \& Boussenna, Y. (2020). Knowledge management and organizational performance: Abdelmalek Essaadi university cases. International Journal of Accounting, Finance, Auditing, Management and Economics, 1(3), 149-168. https://doi.org/10.5281/zenodo.4281558.

[20] Ernest, E ., Ngamoe, B ., Villeneuve, A . (2020). L'influence des pratiques de gestion des connaissances dans le processus de gestion stratégique des TI , International Journal of Business and Technology Studies and Research , ISSN: 2665-7716, Volume 2, Issue 1.

[21] Ghorbani, N,.Watson , L., Zahra, R,.(2011). Dialogical Validity of Religious Measures in Iran: Relationships with Integrative Self-Knowledge and Self-Control of the "Perfect Man", https://doi.org/10.1163/157361211X552209.

[22] Hall \& Donnell, ( 1979). Managerial Achievement: The Personal Side of Behavioral Theory , https://doi.org/10.1177/001872677903200106.

[23] Helms, M., (2006). Encyclopedia of management 5th ed. Marilyn M. Helms, ed., Farmington Hills: Thompson Gale.

[24] Hilman, H., Abubakar, A. (2017). Strategic talent management and university performance: A theoretical perspective. European Journal of Business and Management, 9(4), 35-40. 
BOUSSENNA: Knowledge management and academic performance moderating role of organizational...

[25] Hosseinpour, H \& , Tabari , M ( 2016 ), The relationship between structure and performance organizational from emergency staff viewpoints, Midwifery Sciences 2016: 3(2): 40-46.

[26] Laudon, K. C., et Laudon, J. P. (2007). Sistemas de Informação Gerenciais. São Paulo: Pearson Prentice Hall.

[27] Lee, L.T., \& Sukoco, B.M. (2007). The effects of entrepreneurial orientation and knowledge management capability on organizational effectiveness in Taiwan: the moderating role of social capital, International Journal of Management, 24(3), 549- 73.

[28] Lee, Sh., \& Tseng, P. (2014). The Effect of Knowledge Management Capability and Dynamic Capability on Organizational Performance, Journal of Enterprise Information Management, 27: 1-43.

[29] Li , Y ., Huang, J ., Tsai, M. ( 2009 ). Entrepreneurial orientation and firm prformance: The role of knowledge creation process , Industrial Marketing Management.

[30] Meijaard , J \& J. Brand, M \& Mosselman , M , (2005) , Organizational Structure and Performance in Dutch small Firms, pg 83-96 DOI 10.1007/s11187-005-4259-7.

[31] Mills, A., \& Smith, T. (2011). "Knowledge Management and Organizational Performance: A Decomposed View", Journal of Knowledge Management, 15(1): 156-171.

[32] Nonaka, I., (1994). A Dynamic Theory of Organizational Knowledge Creation. Organization Science, 5(1), pp.14-37.

[33] Novak, A , (2017), KNOWLEDGE MANAGEMENT AND ORGANIZATIONAL PERFORMANCE - LITERATURE REVIEW, Management, Knowledge and Learning , International Conference 2017 Technology, Innovation and Industrial Management.

[34] Patel, V. M., Ashrafian, H., Ahmed, K., Arora, S., Jiwan, S., Nicholson, J. K., Athanasiou, T. (2011). How has healthcare research performance been assessed? A systematic review. Journal of the Royal Society of Medicine, 104, 251-261.

[35] Ramachandran, S., Chong, S., Wong, K. (2013), "Knowledge Management Practices and Enablers in Public Universities: A Gap Analysis, Campus-Wide Information Systems", 30(2): 76-94.

[36] Ranjan , J,. \& Bhatnagar, V,. (2008). Principles for successful aCRM in organizations, Direct Marketing An International Journal 2(4):239-247, DOI: 10.1108/17505930810931035.

[37] Reich ,B ,. Gemino , A,. Sauer , C . (2013). How knowledge management impacts performance in projects: An empirical study, ScienceDirect International Journal of Project Management 32 (2014) 590-602 .

[38] Sahibzada, U., Jianfeng, C. \& Latif, K. (2020). Interpreting the impact of knowledge management processes on organizational performance in Chinese higher education: mediating role of knowledge worker productivity, Studies in Higher Education, Volume 45, Issue 11.

[39] Salama, S ., Isaac, O., Habtoor, N. (2020). Impact of Availability of Knowledge Management Infrastructure on Improving the Performance of The Education Sector Staff in Libya: Organizational Loyalty as a Mediating Variable, International Journal of Management and Human Science (IJMHS), eISSN: 2590-3748 URL: http://www.ijmhs.org.

[40] Shamia et al., (2018) ( Using the Asian Knowledge Model "APO" as a Determinant for Performance Excellence in Universities- Empirical Study at Al -Azhar University- Gaza.

[41] Wenjiao D,. \& Yang H . (2020) . Research on Performance Evaluation of Knowledge Management Innovation in Colleges and Universities, https://doi.org/10.2991/aebmr.k.200708.054, Proceedings of the 4th International Symposium on Business Corporation and Development in South-East and South Asia under B\&R Initiative (ISBCD 2019), ISBN 97894-6252-983-0 . 